\title{
Procedimentos analíticos em perícia ambiental: fracionamento de soluções
}

O fracionamento pode ser dos tipos: fracionamento de soluções sólido-sólido, fracionamento de soluções sólido-gás, fracionamento de soluções líquido-líquido fracionamento de soluções líquido-gás, fracionamento de soluções gás-gás. O fracionamento de soluções sólido-sólido envolve: dissolução fracionada e eletrólise fracionada. Por sua vez o fracionamento de soluções sólido-líquido contempla destilação simples, cristalização fracionada, extração fracionada e precipitação fracionada. O fracionamento de soluções líquido-líquido inclui: destilação fracionada, solidificação fracionada e extração fracionada. $O$ fracionamento de soluções gás-gás contém liquefação fracionada, difusão fracionada, adsorção seletiva, dissolução fracionada e destilação fracionada.

Palavras-chave: Fracionamento de soluções; Perícia ambiental; Procedimentos; Meio ambiente.

\section{Analytical procedures in environmental expertise: fractionation of solutions}

The fractionation can be of the types: fractionation of solid-solid solutions, fractionation of solid-gas solutions, fractionation of liquid-liquid solutions, fractionation of liquid-gas solutions, fractionation of gas-gas solutions. The fractionation of solid-solid solutions involves: fractional dissolution and fractional electrolysis. In turn the fractionation of solid-liquid solutions includes simple distillation, fractional crystallization, fractional extraction and fractional precipitation. The fractionation of liquid-liquid solutions includes: fractional distillation, fractional solidification and fractional extraction. The fractionation of gas-gas solutions contains fractional liquefaction, fractional diffusion, selective adsorption, fractional dissolution and fractional distillation.

Keywords: Fractionation of solutions; Environmental expertise; Procedures; Environment.

Topic: Biotecnologia

Reviewed anonymously in the process of blind peer.
Received: $12 / 08 / 2020$

Approved: $15 / 12 / 2020$
Camilo Pinto de Souza (ic)

Universidade Federal Rural do Rio de Janeiro, Brasil http://lattes.cnpq.br/5526361137852985

http://orcid.org/0000-0002-5354-3194 camilo.p.souza18@gmail.com

Cleber Vinicius Vitorio da Silva (iD

Universidade Federal Rural do Rio de Janeiro, Brasil http://lattes.cnpq.br/4275890458575782

http://orcid.org/0000-0001-8337-9615

clebervitorio88@gmail.com

\section{Evandro Lima (id}

Universidade Federal Rural do Rio de Janeiro, Brasil

http://lattes.cnpq.br/7057930279111732

http://orcid.org/0000-0003-4213-9652

evandrolimaabpg@uol.com.br

\section{Gustavo Aveiro Lins (D)}

Universidade Federal Rural do Rio de Janeiro, Brasil

http://lattes.cnpq.br/5173989372426437

http://orcid.org/0000-0002-0244-6925

gustavoaveiro@gmail.com

Josimar Ribeiro de Almeida (iD

Universidade do Estado do Rio de Janeiro, Brasil

http://lattes.cnpq.br/3215586187698472

http://orcid.org/0000-0001-5993-0665

almeida@poli.ufri.br

Lais Alencar de Aguiar (iD)

Comissão Nacional de Energia Nuclear, Brasil

http://lattes.cnpq.br/5785500333245448

http://orcid.org/0000-0002-1551-4085

aguiar.lais@gmail.com
Raphael do Couto Pereira (iD

Escola Naval, Brasil

http://lattes.cnpq.br/2232319377341816

http://orcid.org/0000-0002-3934-4332

rcoutopereira1@gmail.com d

DOI: 10.6008/CBPC2674-6441.2020.002.0003

\section{Referencing this:}

SILVA, C. V. V.; LENZ, E. R. S.; LINS, G. A.; ALMEIDA, J. R.; AGUIAR, L. A. Procedimentos analíticos em perícia ambiental: fracionamento de soluções. Naturae, v.2, n.2, p.14-22, 2020. DOI: http://doi.org/10.6008/CBPC2674-6441.2020.002.0003 


\section{INTRODUÇÃO}

O Perito Ambiental deve ter o conhecimento das condições em que cada método é confiável e a consciência das interferências possíveis que podem ocorrer, e ser capaz de imaginar caminhos para evitar estes problemas. Uma das decisões principais, a ser tomada pelo Perito Ambiental, é a da escolha do procedimento mais eficiente de uma dada análise; para chegar à decisão correta, o Perito Ambiental deve ter familiaridade com os detalhes práticos das diversas técnicas e com os princípios teóricos sobre os quais se baseiam. Dispondo-se de uma amostra apropriada, é necessário que o Perito Ambiental dedique atenção à técnica, ou às técnicas, mais convenientes de serem empregadas para as determinações requeridas (ALMEIDA et al., 2019). O Perito Ambiental terá atenção às questões relativas à exatidão e à precisão esperada dos métodos dados e, além disso, não deve desprezar fatores como tempo e custo. $O$ método mais exato para certa determinação pode ser muito demorado ou envolver o uso de reagentes caros. Por tal motivo, o apropriado é avaliar que exatidão se faz necessária. Em muitos casos, é possível escolher um método que, embora menos exato, proporcione, num tempo razoável, resultados satisfatórios (ALMEIDA et al., 2019).

\section{RELATO}

São três os fatores principais que influenciam a adoção de métodos clássicos: A aparelhagem necessária para os procedimentos clássicos custo econômico justo e encontra se com facilidade em todos os laboratórios; no entanto, alguns instrumentos/aparelhos são Instrumentação típicos de Ciência Forense tem elevado custo. De forma que sua adoção só se justifica quando são muitas as amostras a analisar, ou quando se trata da determinação de substâncias em quantidades diminutas (análise de traços, subtrações ou ultratraços). Nos métodos instrumentais é necessário efetuar uma operação de calibração, em que se usa amostra do material com a composição conhecida como a substância de referência. Enquanto um método instrumental é o ideal para a execução de muitas determinações de rotina, no caso de uma análise episódica, fora da rotina, é muitas vezes mais simples usar um método clássico do que ter o trabalho de preparar os padrões indispensáveis e calibrar o instrumento. Importante destacar que as pesquisas orientadas pelo método dialético revelam a historicidade do fenômeno e suas relações, em nível mais amplo, situam o problema dentro de um contexto complexo, ao mesmo tempo, estabelece e aponta as contradições possíveis dentre os fenômenos investigados. A investigação qualitativa é alicerçada na inseparabilidade dos fenômenos e seu contexto, pois, as opiniões, percepções e significados serão compreendidos com maior profundidade a partir da contextualização. A validade seria referente à semelhança entre o conceito e suas medidas, ao grau em que uma medida representa precisamente o que se espera. A garantia da validade começaria com a compreensão direta do que deve ser medido, sendo, portanto, uma questão de formulação da pesquisa.

O método proposto foi dividido em três fases, as quais foram subdivididas em etapas para a realização do levantamento bibliográfico. Na primeira fase da pesquisa (Perguntas de pesquisa) verifica-se as principais decisões e definições acerca da pesquisa. As perguntas de pesquisa, ficam em destaque e servem 
como impulsos para o início da revisão. Define-se o tema para realizar o levantamento bibliográfico e o período disponível. Outras decisões são tomadas simultaneamente. Tais como a definição das palavraschave, para atuarem como identificadores. Paralelamente, resumem os principais assuntos sobre o tema a se pesquisar; assim como as combinações das palavras-chave. Essas, por sua vez, podem ser feitas por meio da utilização dos operadores booleanos e em diferentes bases de dados tais como Portal de Periódicos CAPES, Base de dados SCIELO, Publish or Perish, EBSCO, entre outras. No presente caso, as bases de dados foram Web of Science (ou ISI), Plataforma SUSTENERE, Scielo e Scopus. Essas bases possuem fácil acesso, permitindo, por meio de suas ferramentas, uma pesquisa criteriosa seja realizada, abrangendo uma vasta quantidade de periódicos. A segunda fase (Seleção dos artigos) inicia o levantamento e a seleção dos artigos, utilizando-se dos critérios de exclusão. Utiliza-se das palavras-chave de exclusão para realizar classificação mais criteriosa dos artigos. Delimitando também o período. Na etapa seguinte ocorre o primeiro filtro dos artigos, faz-se uma seleção a partir dos títulos, identificando os não alinhados. Na próxima etapa se faz a leitura dos resumos para excluir os impertinentes ao tema pesquisado. A etapa seguinte contém uma análise subjetiva do pesquisador para identificar, nos artigos alinhados ao tema, aqueles que possuem maior relevância acadêmica. Uma análise bibliométrica indica a relevância do autor/artigo para a composição do referencial bibliográfico. A Fase 3 corresponde a Classificação dos artigos selecionados. Procede-se a organização das amostras de artigos selecionados. O objetivo é ordenar, um padrão que vai variar de acordo com a necessidade do pesquisador e a prioriza como foco para desenvolvimento temático. Evidencia-se a importância da análise minuciosa dos artigos que compõem a amostra.

Em pesquisas qualitativas, a concepção de validade assume formas distintas, pois a discussão sobre escalas de medição não se aplica a métodos qualitativos, sendo necessária a compreensão da validade em outra perspectiva. Um atributo que se relaciona com a objetividade, com a possibilidade de repetição do experimento, com o fato de a pesquisa estar aberta à verificação por outras pessoas e com a capacidade de generalização (ALMEIDA, 2019). A validade pode ser vista genericamente como a correspondência entre a pesquisa e a realidade. Ela se refere à verificação dos resultados como verdadeiros e confiáveis. Ela estaria relacionada ao fato de os resultados refletirem com precisão a situação analisada e serem confiáveis, no sentido de que não haveria razões para deles duvidar; ou seja, a pesquisa é válida se as evidências fornecem o apoio necessário às suas conclusões (SOUZA et al., 2011). A intenção não é generalizar, mas sim descrever, analisar, buscar compreender.

\section{DISCUSSÃO}

\section{Fracionamento de soluções sólido-sólido}

\section{Dissolução fracionada}

Nesta técnica emprega-se um solvente capaz de reagir seletivamente com um dos componentes do sistema; separa-se por filtração o sólido que não reagiu com o solvente. 


\section{Eletrólise fracionada}

Esta técnica é utilizada na análise quantitativa de ligas metálicas. Dissolve-se a liga em um solvente adequado, realizando-se depois a eletrólise da solução. Empregando-se diferenças de potenciais adequados e condições convenientes, é possível separar totalmente cada metal da liga.

\section{Fracionamento de soluções sólido-líquido}

\section{Destilação simples}

Nesta técnica submete-se o sistema a aquecimento de modo que o líquido entre em ebulição. Os vapores formados são então condensados e retornando ao estado líquido. Este processo é comumente empregado para a obtenção de água pura (água destilada) a partir de água potável que contém gases e sólidos dissolvidos. À medida que o sistema se aquece há desprendimento dos gases dissolvidos e ao iniciar-se a ebulição não restam mais gases em solução; os vapores que se formam ao passar pelo condensador são de água pura. Ao terminar a operação, os sólidos permanecem no balão de destilação desde que sejam voláteis.

\section{Cristalização fracionada}

Neste processo evapora-se parcialmente o líquido até que a solução se torne saturada, ocasião em que ocorre a cristalização do sólido. O sistema heterogêneo assim formado é posteriormente fracionado através de técnica conveniente, como por exemplo, filtração.

\section{Extração fracionada}

Este processo baseia-se na seguinte técnica: quando se adiciona um sólido a uma mistura de dois líquidos imiscíveis, agita-se o sistema heterogêneo, deixando-o em repouso para que se separem as duas fases, observando-se que o sólido se distribui entre os dois líquidos, estabelecendo-se relação entre a concentração desse sólido em ambos os líquidos iguais à relação entre as concentrações das respectivas soluções saturadas.

\section{Precipitação fracionada}

Neste processo adiciona-se à solução uma substância que provoca a precipitação do sólido dissolvido, podendo-se operar quer por saturação, quer por mudança de solvente.

\section{Fracionamento de soluções sólido-gás}

Esta técnica é realizada a quente, sendo empregada na recuperação do etanol. Os vapores de etanol são adsorvidos em carvão ativo e da solução obtida o álcool comum é extraído, por tratamento com vapor d'água. 


\section{Fracionamento de soluções líquido-líquido}

A extração líquido-líquido é uma técnica em que uma solução (usualmente aquosa) é posta em contato com um segundo solvente (usualmente orgânico), essencialmente imiscível com o primeiro solvente, a fim de provocar uma transferência de um, ou mais, soluto para o segundo solvente. As separações que se podem fazer são simples, limpas, rápidas e convenientes. Em muitos casos a separação pode ser efetuada pela agitação, durante alguns minutos, num funil de separação. A técnica é igualmente aplicável a materiais no nível de traço e a grandes quantidades de material. No caso de solutos inorgânicos, estaremos confrontados, na maior parte das vezes, com amostras em soluções aquosas, de modo que é necessário formar substâncias - como, por exemplo, quelatos de metais, neutros, ou complexos de associação iônica que possam ser extraídas por solventes orgânicos. Com os solutos orgânicos, no entanto, o sistema de extração pode envolver, às vezes, dois solventes orgânicos imiscíveis no lugar do tipo de extração solução aquosa- solução orgânica. A técnica de extração líquido-líquido foi, como é natural, amplamente usada para separar os componentes de sistemas orgânicos; em particular, a extração por solvente pode ser usada para conseguir uma 'purificação' e para concentrar os solutos de interesse, antes da análise. O procedimento de extração envolve duas fases orgânicas (isto é, não há fase aquosa presente) e que a miscibilidade se minimiza pela saturação de cada solvente pelo outro. Os procedimentos de extração para espécies orgânicas não possuem em geral, o mesmo grau de seletividade que pode ser conseguido nos sistemas contendo metais, e a principal aplicação analítica da extração por solvente é a determinação de metais como constituintes menores, ou traços, em diversos materiais inorgânicos e orgânicos. Embora a extração por solvente tenha sido usada, predominantemente. Para o isolamento e a pré-concentração de uma única espécie, antes da sua determinação, pode também ser aplicada à extração de grupos de metais ou de classes de compostos, antes da respectiva determinação, mediante técnicas como a absorção atômica ou a cromatografia. O melhor método de extração, com um dado volume de líquido de extração, é o de empregar o líquido em diversas parcelas em lugar de utilizar todo o volume numa só extração.

\section{Destilação fracionada}

Esta técnica física consiste em separar por aquecimento uma mistura homogênea de líquidos dotados de diferentes pontos de ebulição. Os vapores do líquido de menor ponto de ebulição são condensados e recolhidos, verificando-se que o líquido separado é constituído quase exclusivamente desse líquido de maior volatilidade. A prática experimental demonstra que quanto maior a diferença dos pontos de ebulição de uma mistura miscível de líquidos, mais fácil será a separação deles; reciprocamente, quanto mais próximas forem estas temperaturas, mais difícil ou mesmo impossível será a separação dos componentes por destilação fracionada, como são os casos de sistemas água-etanol, benzeno-etanol, água-benzeno. Quando a mistura de dois líquidos é muito difícil de ser separada, devido à proximidade de seus respectivos pontos de ebulição, emprega-se uma coluna de fracionamento. 


\section{Solidificação fracionada}

Este processo baseia-se no seguinte: quando se resfria uma solução de líquidos dotados de diferentes temperaturas de solidificação, os primeiros cristais que se obtém são constituídos pela substância de maior temperatura de fusão, isto é, de temperatura mais próxima do ambiente. Assim, por exemplo, resfriando-se uma mistura de benzeno e de tolueno, dá-se a solidificação do benzeno a $5,5^{\circ} \mathrm{C}$ e a do tolueno a $-95^{\circ} \mathrm{C}$. Consequentemente, baixando-se a temperatura, o benzeno a $5,5^{\circ} \mathrm{C}$ separa-se do tolueno facilmente. No novo sistema assim obtido, benzeno-sólido e tolueno-líquido, o benzeno é separado do tolueno praticamente puro.

\section{Extração fracionada}

Este processo, cujo princípio é análogo ao de extração para fracionamento de sistemas sólido-líquido, é empregado na análise orgânica elementar na pesquisa de halogêneos, e no reconhecimento do bromo, que é sensivelmente mais solúvel no éter comum do que em água. A extração por solvente é, em geral, empregada na análise para separar um soluto (ou solutos) de interesse de outras substâncias que interferem com a análise quantitativa final do material; em alguns casos, os solutos interferentes são extraídos seletivamente. A extração por solvente também é usada para concentrar uma espécie que numa solução aquosa está muito diluída para ser analisada. A escolha do solvente para a extração é governada pelas seguintes considerações: razão de distribuição elevada para o soluto e razão de distribuição baixa para as impurezas indesejáveis; Solubilidade baixa em fase aquosa; Viscosidade suficientemente baixa e diferença de densidade suficiente em relação à fase aquosa, a fim de evitar a formação de emulsões; Toxidez e inflamabilidade baixas; Facilidade de recuperação do soluto no solvente, para o processamento analítico subsequente. Assim, quando for possível uma escolha, merecem atenção o ponto de ebulição do solvente e a facilidade de extração por reagentes químicos. Algumas vezes é possível usar solventes mistos para realçar as propriedades mencionadas. Os agentes de salificação precipitante também podem melhorar a extratibilidade. A extração pode ser feita numa operação descontínua (em batelada) ou numa operação contínua. A extração em batelada, o método mais simples e o mais amplamente utilizado, emprega-se quando se pode alcançar com facilidade uma grande razão de distribuição, para a separação desejada. Um pequeno, número de extrações remove fácil e completamente o componente desejado e podem ser feitas num simples funil de separação. As duas camadas são agitadas no funil de separação até que se tenha atingido o equilíbrio e são separadas depois de assentarem completamente. A extração e a separação devem ser feitas em temperatura constante, pois a razão de distribuição, e os volumes do solvente, são influenciados pelas modificações de temperatura, a agitação muito violenta da mistura de extração não proporciona qualquer benefício: é suficiente a inversão repetida do vaso para se atingir o equilíbrio em alguns poucos movimentos. Se gotículas da fase aquosa forem arrastadas pelo extrato orgânico, é possível removê-las mediante a filtração do extrato, com um papel de filtro seco; o papel de filtro deverá ser lavado várias vezes com o solvente orgânico puro. Quando a razão de distribuição for baixa, usa-se o método de extração contínua. Este procedimento emprega uma corrente contínua do solvente imiscível, que flui através da solução; se o solvente for volátil, reciclá-lo por destilação 
e condensação e fazer a dispersão na fase aquosa por meio de um disco dei vidro sinterizado, ou de outro dispositivo equivalente a este. Existem aparelhos que fazem extrações contínuas com o retorno automático do solvente volatilizado.

\section{Extração do soluto no extrato}

Esta extração é a remoção do soluto no extrato da fase orgânica a fim de prepará-lo para a análise detalhada. Em muitos procedimentos analíticos que envolvem um processo de extração, no entanto, a concentração do soluto desejado é determinada diretamente na fase orgânica. No entanto, quando se forem empregar outros métodos de análise, ou quando forem necessários outros estágios de separação, o soluto deve ser removido da fase orgânica para um meio mais conveniente. As impurezas presentes na fase orgânica podem ser, algumas vezes, removidas por uma retrolavagem. $\mathrm{O}$ extrato orgânico é agitado com uma, ou com mais de uma, pequena porção da fase aquosa pura, contendo a concentração ótima do reagente e com o pH correto; com isto se provoca a redistribuição das impurezas em favor da fase aquosa, pois as suas razões de distribuição são baixas, enquanto a maior parte do elemento desejado permanecerá na camada orgânica. A técnica da extração por solvente permite a separação, e muitas vezes a pré-concentração, de um elemento ou de uma substância particular (ou de um grupo de elementos ou de substâncias). A etapa final de análise, em seguida a este procedimento de separação, envolve a determinação quantitativa das espécies de interesse, mediante uma técnica apropriada. Os métodos espectrofotométricos podem ser muitas vezes, aplicados diretamente ao extrato utilizando-se a absorção da espécie extraída na região do ultravioleta ou do visível. Outras técnicas que podem ser aplicadas diretamente ao extrato são a espectrofotometria de chama e a espectrofotometria de absorção atômica (AAS). O uso direto do extrato na espectrofotometria de absorção atômica pode ser vantajoso, pois a presença do solvente orgânico em geral realça a sensibilidade do método. Entretanto, as duas principais razões para incluir uma separação química na preparação de uma amostra para a espectrofotometria de absorção atômica são: (a) a concentração do elemento a ser determinado estar abaixo do limite de detecção depois da preparação normal da solução da amostra; e (b) a necessidade de separarem-se as espécies de interesse de outros solutos em concentração excessiva, que afetam o sistema nebulizador e o sistema combustor, ou então propiciam efeitos de interferência química muito intensos. A extração por solvente é, possivelmente, a técnica de separação mais amplamente usada em conjunção com a espectrofotometria de absorção atômica. Muitas vezes ela permite a extração de vários elementos em uma só operação e, em virtude da natureza específica da espectrofotometria de absorção atômica, podem ser usados reagentes não-seletivos na extração líquido- líquido. Também se descreveram análises de multielementos envolvendo a extração por solvente e a cromatografia líquida de alta eficiência (HPLC). Os extratos, com os complexos quelatos metálicos de reagentes contendo enxofre, como a ditizona e o dietilditiocarbamato, foram usados diretamente na determinação dos metais pela cromatografia líquida de alta eficiência. 


\section{Fracionamento de soluções líquido-gás}

O fracionamento de soluções líquido-gás é realizado usualmente por aquecimento, pois a elevação da temperatura do sistema provoca diminuição da solubilidade do gás no líquido, solubilidade esta que praticamente se torna nula na ebulição. Através desta técnica são eliminados gases dissolvidos na água, como o O2 e o N2.

\section{Fracionamento de soluções gás-gás}

\section{Liquefação fracionada}

Para a aplicação deste processo é necessário que haja apreciável diferença entre as temperaturas de liquefação dos gases presentes na solução.

\section{Difusão fracionada}

Este processo baseia-se no fato de que mistura de gases de densidades diferentes, difunde através de uma parede porosa com uma velocidade inversamente proporcional à sua densidade; assim, quanto menor a densidade do gás contido na mistura, maior será sua velocidade de passagem pela superfície porosa. Realizando-se esta difusão sucessivas vezes, é possível proceder a separação dos constituintes da mistura gasosa em termos praticamente quantitativos.

\section{Adsorção seletiva}

Neste processo submete-se a solução a uma substância específica que adsorve seletivamente um dos componentes da mistura. Emprega-se frequentemente o carvão ativo. Sob o ponto de vista criminalístico, é no processo de adsorção seletiva que se baseia o emprego de máscaras contra gases tóxicos que contaminam a atmosfera.

\section{Dissolução fracionada}

Esta técnica fundamenta-se no emprego de uma substância que é capaz de dissolver um dos componentes da mistura sem afetar os demais.

\section{Destilação fracionada}

Neste processo liquefaz-se plenamente a mistura gasosa e destila-se fracionadamente a solução líquida obtida.

\section{CONSIDERAÇÕES FINAIS}

Dispondo-se de uma amostra apropriada, é necessário que o Perito Ambiental dedique atenção à técnica, ou às técnicas, mais convenientes de serem empregadas para as determinações requeridas. O Perito Ambiental terá atenção às questões relativas à exatidão e à precisão esperada dos 
métodos dados e, além disso, não deve desprezar fatores como tempo e custo. 0 método mais exato para certa determinação pode ser muito demorado ou envolver o uso de reagentes caros. Por tal motivo, o apropriado é avaliar que exatidão se faz necessária. Em muitos casos, é possível escolher um método que, embora menos exato, proporcione, num tempo razoável, resultados satisfatórios.

\section{REFERÊNCIAS}

ALMEIDA, J. R.; SILVA, C. E.; SILVA, C. V. V.; AGUIAR, L. A.; GARCIA, V. S.; SOUZA, C. P.; LENZ, E. R. S.; LINS, G. A.; ALMEIDA, S. M.. Multifatorialidade em saúde ambiental. Environmental Scientiae, v.1, p.26-47, 2019. DOI: https://doi.org/10.6008/CBPC2674-6492.2019.002.0002

ALMEIDA, J. R.; SILVA, C. E.; SILVA, C. V. V.; AGUIAR, L. A.; GARCIA, V. S.; SOUZA, C. P.; LENZ, E. R. S.; LINS, G. A.; ALMEIDA, S. M.. Política e economia de vigilância em saúde ambiental. Environmental Scientiae, v.1, p.1-25, 2019. DOI:
https://doi.org/10.6008/CBPC2674-6492.2019.002.0001

SOUZA, F. M. N.; SILVA, C. E.; AGUIAR, L. A.; ALMEIDA, J. R.. Proposta para utilização da simulação computacional em análise de risco, avaliação de desempenho e sistemas de gestão ambiental. Revista Ibero-Americana de Ciências Ambientais, v. 2, p. 39-63, 2011. DOI:

https://doi.org/10.6008/ESS2179-6858.2011.002.0003

A CBPC - Companhia Brasileira de Produção Científica (CNPJ: 11.221.422/0001-03) detém os direitos materiais desta publicação. Os direitos referem-se à publicação do trabalho em qualquer parte do mundo, incluindo os direitos às renovações, expansões e disseminações da contribuição, bem como outros direitos subsidiários. Todos os trabalhos publicados eletronicamente poderão posteriormente ser publicados em coletâneas impressas sob coordenação da Sapientiae Publishing, da Companhia Brasileira de Produção Científica e seus parceiros autorizados. Os (as) autores (as) preservam os direitos autorais, mas não têm permissão para a publicação da contribuição em outro meio, impresso ou digital, em português ou em tradução. 